\title{
From Beveridge to Borrie and Beyond
}

As this issue of the Journal goes to press, the report of the Commission on Social Justice has appeared. This independent enquiry into social and economic reform in the UK, set up in December 1992 at the instigation of the late John Smith QC MP, then leader of the Labour Party, was modelled on a Royal Commission. But with the Labour Party remaining in opposition, the enquiry was conducted under the auspices of the Institute for Public Policy Research and chaired by Sir Gordon Borrie, most recently Director-General of Fair Trading. The Commission was charged with the task of reviewing social policy fifty years on from the Beveridge Report on Social Insurance and Allied Services and setting out a new agenda for social and economic renewal in the context of an 'intelligent' welfare state.

We wish to signal the appearance of Social Justice: Strategies for National Renewal since we hope that this somewhat polemical document will be widely read and its controversial policy proposals carefully discussed. We assume that, given its innovative character as an independent policy statement, it will be of considerable interest to all our readers including our overseas subscribers. It offers a focal point for debate on a variety of current issues of social policy, with a resonance far beyond the UK.

Social Justice, however, remains firmly within the tradition of bipartisan consensual politics on the welfare state and takes as its clear starting point the Beveridge report with its five 'giant evils' of want, disease, ignorance, squalor and idleness to be slain by social policies provided and supported by the state. The report therefore offers an antidote to the last fifteen years of Conservative rule with their emphasis clearly on the free market economy and 'business' strategies to deal with current social and economic problems. The Commission offers a panoramic account of recent social and economic change and a vision - rather than a strategic plan - for the future beyond the year 2010. However, given that it is rooted firmly in the Beveridge tradition its central focus is also on social insurance and income maintenance, but highlighting the continuing and indeed growing insecurities of the contemporary labour market. Like the Beveridge report, Social Justice is much more muted, and, in fact, rather inconsistent on the 'allied services'.

Borrie and his colleagues alert us to the current five 'evils' and add a new one variously described as discrimination and/or racial discrimination. This is somewhat inconsistent with their rather dated review 


\section{Miriam David and Dulcie Groves}

of the current 'state of the nation' which appears still committed to the model of a male breadwinner, with a part-time working wife and mother of his children, as opposed to the full-time home-making wife of fifty years ago.

The values of social justice are clearly articulated as: the equal worth of all citizens, their equal right to be able to meet their basic needs, the need to spread opportunities and life chances as widely as possible, and finally the requirement that we reduce and where possible eliminate unjustified inequalities. However, these values are inextricably linked to promoting economic success. Thus four propositions run through the various policy proposals, namely first, transforming the welfare state from a safety net to a springboard for economic opportunity; second, improving access to education and training and investing in the talent of all our people, third, promoting real choices across the life-cycle for men and women in the balance of employment, family, education, leisure and retirement; and fourth, reconstructing the social wealth to ensure a dependable social environment. However, this rhetoric of equal opportunities is not matched within the limited social and economic analysis of the state of the nation nor in the specific and often contradictory policy proposals which include the following.

The Commission makes the case for a reformed social insurance system which can operate effectively in relation to a radically changed labour market in which women and men alike will need to maximise their capacity to obtain formal educational qualifications at various stages in their lives and repeatedly update their vocational skills, interspersing full and part-time paid work with unpaid work in the home and leisure pursuits. It also makes a case for investment in 'social capital' - family-friendly social policies, good public services, housing and a thriving civic culture. Social Justice also argues for an Investors' Britain, combining 'the ethics of community with the dynamics of the market economy' in a socially just society.

Readers will variously find many points to debate, criticise, reject or endorse in this report - often infuriating, simultaneously bland and complacent, yet always challenging. We keenly await its impact on both our readership and the wider society, but fear that its accessibility may be seriously in doubt, given its relative unavailability to the 'man in the street' even in central London book supermarkets!

\section{Miriam David and Dulcie Groves}

